\title{
PHYSICAL METHODS IN THE TREATMENT OF RHEUMATIC DISORDERS
}

\author{
By William Tegner, F.R.C.P. \\ Phy'sician-in-Charge, the Department of Physical Medicine, The London Hospital
}

Physician, The Arthur Stanley Institute for Rheumatic Diseases

\section{Introduction}

The rheumatic disorders comprise a very wide range of conditions. Many classifications of these disorders have been devised, some of which have been complicated and others relatively simple. For the purpose of discussing physical treatment it is perhaps most convenient to use the simplest of all classifications and to divide the disorders into those that affect the bones and joints, that is, the arthritides, and those that affect other anatomical structures and are commonly known as soft tissue rheumatisms. The treatment of the rheumatic disorders has traditionally been associated with the use of physical agents. The prescription of the use of such agents is the sphere of the doctor who is responsible for the diagnosis of the nature of the rheumatic condition; the treatments themselves are normally carried out by physiotherapists. It is a remarkable thing that, while doctors have recently shown themselves deeply interested in the scientific study of the value of these treatments, physiotherapists have shown themselves more willing to accept the empirical teaching of their predecessors. Many treatments have been subjected to controlled investigations, and the results of treatment have been subjected to statistical analysis. On the part of doctors, this has led to a definite swing away from empiricism to a scientific appraisal of value and the rejection of any traditional forms of physical treatment which cannot justify themselves under scientific scrutiny. Physiotherapists, on the other hand, have shown signs of alarm that their favourite prescriptions should be looked at askance, and have even expressed fears for their livelihood should such ruthless scrutiny of their work go on. Yet there is no justification for such fears. The work of the physiotherapist in the management of the rheumatic disorders is just as important as ever it was, and the amount of work being entrusted to them is increasing not decreasing.

\section{Arthritis}

In dealing with arthritis there is no question of the great importance of applying correct physical treatment. The basic principles which guide us 3 . must be the treatment of the condition and its $\dot{\omega}$ cause, the relief of symptoms, the prevention of $\vec{\omega}$ deformity and permanent damage, and the restoration of optimum function.

\section{Osteoarthritis}

In osteoarthritis we are faced by a degenerative condition in which the pathological changes, once established, are irreversible. In its most serious forms it attacks the weight-bearing joints-the hip $\frac{\mathbb{}}{3}$ and the knee, while the ankle joint, owing to the presence of that admirable ball bearing, ta astragalus, usually escapes damage. But this ty?e of arthritis is compatible with excellent generâl. health and is therefore all the more irksome to the patient. Very many electrotherapeutic manoeuvres have been claimed to be of value in relieving pain, $\bar{\partial}$ such as the passage of the constant current and various ionizations. It is highly doubtful if these $\stackrel{\varnothing}{\varnothing}$ have any value. Traditionally heat is a great $\vec{F}$ soother of pain, and superficial heat in the form of $\stackrel{0}{\exists}$ infra red irradiations or deep heat in the form of diathermy is often prescribed. There is no magic inherent in such terms as infra red and diathermy both are simply forms of heat, and heat may soothe 3 . pain and, to some extent, increase vascularity. Such treatments are applied passively to a patient $\underline{-}$. who plays no personal part in his own treatment.o Far more important than these are the education of $₹$ the patient in how to combat his own disability, 을 how to maintain his own musculature correctly $>$ according to mechanical principles, and how to을. combine rest and activity along sound lines. Damage to the joint caused by osteoarthritis will reflexly set in motion false body mechanics, mani- $N$ fested by the wasting of muscle and a deformity pattern which will be perpetuated by a viciouso circle of pain causing wasting and deformity, ando wasting and deformity causing pain. To combat this it is essential that correct alignments and? muscle function should be restored and thato muscle which is the prop of the damaged jointo 
should be hypertrophied. To achieve this the physiotherapist or remedial gymnast must work with energy and patience. The work of the medical auxiliary must be very largely educative and preventive, and she must herself be taught to realize that her influence and guidance are much more important that the application of various electrical treatments. The correct prescription of rest and activity is of paramount importance. Damaged joints may have to be rested but too much rest will itself lead to fibrosis and atrophy. To exercise a leg with damaged joints by means of weight-bearing activities will, in the acute stages, only aggravate the damage. It is here that nonweight-bearing exercises play such an important part. By means of these the props of the damaged joints are built up and strengthened to play their part when weight-bearing can be resumed. By modern techniques non-weight-bearing activities can be progressed to the stage of exercise against resistance, which is the only satisfactory method of building up strong muscles. The patient must be educated to adapt himself to his disability. He must learn that both excess of rest and excess of exercise may be harmful. Walking as a hobby must be abandoned, but a bath chair life can be avoided. There is no doubt that with care and guidance the majority of patients suffering from osteoarthritis can learn to lead a tolerable life.

\section{Rheumatoid Arthritis}

Rheumatoid arthritis differs from osteoarthritis in being a generalized systemic disease, as opposed to a localized disease of joints. Thus the patient is potentially much more ill than the sufferer from osteoarthritis and, in the acute stage, should preferably be treated in bed in hospital. Here again physical treatment is of importance and the daily session with the physiotherapist is essential. We are still groping for a satisfactory treatment of the general condition by drug or hormone or antibiotic, and this means that we must rely on what facts we already know about the condition to guide us in its management. We know that it is a disease of exacerbations and remissions and that in the majority of cases we can hope for eventual quiescence, but we also know that the ill-guided patient may end as a cripple even if the disease eventually becomes quiescent.

\section{Care of the Knees}

It should be realized from the very first that the majority of those crippled by rheumatoid arthritis are crippled through flexion deformities of the knees and that prevention of flexion deformities is one of the first duties of the physician and of the physiotherapist. The knees may have to be rested but the position of rest must always be full ex- tension. The knee may have to be supported but support must be given by plaster splints in extension never by pillows or cushions under the knees. In combination with the rest in splints there must be the daily session with the physiotherapist in which the muscles are kept in good order by a carefully planned programme starting with static muscle contractions, going on to assisted movements and progressing to exercise against resistance. The plan for the knees is the most important for if they are neglected the possibility of the patient becoming crippled is so very much increased. Nevertheless the basic principle of splinting in good position and building up of muscles by active work holds good for all joints. Rigid continuous splinting is seldom necessary and splints may frequently have to be renewed as supportive rest relieves muscle spasm and the relief of muscle spasm permits of increased range of movement. It is still necessary, even in these days, to make quite certain that no over-enthusiastic medical auxiliary exerts passive movements on the joints of the rheumatoid arthritic. Such manipulations can do untold harm. Apart from the essential part to be played in education of muscle there is very little evidence that many of the traditional treatments carried out by the physiotherapists are of any actual value. Thus to massage a patientmay be soothing but it will not be of much value and the various types of so-called therapeutic electricity are probably equally useless.

\section{Occupational Therapy}

The occupational therapist may prove a very useful member of the team that looks after the rheumatoid arthritic, not so much because of traditional basket making and rug weaving but from the point of view of the re-education of the patient in resuming the occupation of living unaided. Modern occupational therapy departments are equipped to help the patient in learning to carry out the daily activities of hygiene and independent existence and to provide the housewife with suitably modified utensils to enable her to do some of the housekeeping. The psychological effect of learning once more to rely on one's own efforts is of great value in the management of the rheumatoid arthritic who has been in danger of becoming crippled.

\section{Soft Tissue Rheumatism}

The most remarkable trend in soft tissue rheumatism of recent years has been the rejection of the concept of fibrositis first propounded by Gowers and later elaborated by Stockman. Formerly it was only too easy to diagnose a muscular pain as arising from fibrositis and to treat it with heat and massage. But with increasing 
impetus the critical examination of fibrositis led it to totter and then to crumble. Muscular pain now demands careful examination and investigation before correct treatment can be prescribed. The awakening awareness of the various syndromes which can be evoked by protrusions of the intervertebral discs, both cervical and lumbar, have directed therapy to the cause, not to the site of the pain, and the increase in knowledge of the importance of the anatomical structures surrounding the shoulder joint have led us to stop diagnosing periarticular fibrositis of the shoulder and to attempt a more accurate assessment of the pathological condition which exists. Many other instances could be given of advances in knowledge which have led to more accurate diagnosis. Such a rejection of the concept of fibrositis has dealt a very severe blow to the prescription of massage as a therapeutic weapon. Massage may have a limited part to play in medicine, but the masseuses are fighting a rearguard action in its defence. It has little part to play in the treatment of rheumatism. Heat still seems to have some success in relieving the pain of muscular spasm, and is still extensively prescribed. On the other hand, clinicians are apt to wonder if one is really justified in relieving a protective muscular spasm by such means if the underlying cause of the spasm is left untreated. Other treatments involving the electric current, ultra violet rays and suchlike seem nowadays to have very little part to play. But again physical methods of treatment are still of gre importance in the soft tissue rheumatisms. In the case of the protruded disc we know what spinal movement leads to the danger of this occurring we know what positions and postures increase of decrease this danger and we think that by corre exercise and by postural instruction we can relie the immediate condition and educate the patient ayoiding further recurrences. Thus the physie therapist comes into her own once more and inga much more scientific way. Similarly in the treatment of the various other types of soft tissue rheumatism the basic principles are the same One needs an accurate diagnosis of the cause of the trouble; one aims at the relief of the pain, if the should be necessary, either by the exhibition $\overline{\theta f}$ salicylate or possibly by heat; and one needs careful maintenance of mobility and muscle powers by properly carried out muscular contraction.

\section{Conclusions}

There has been a recent tendency to clarify and appraise the true value of physical methods treatment. Many claims to the efficacy of variogs treatments have not stood the test of scientific scrutiny. The fundamental principles which gưide us now are accurate diagnosis; careful mgin tenance of muscle power and mobility by meats of painstaking supervision on the part of the phsiotherapist and active effort on the part of the patient

\section{RUTHIN CASTLE, NORTH WALES}

A Clinic for the diagnosis and treatment of Internal Diseases (except Mental or Infectious Diseases). The Clinic is provided with a staff of doctors, technicians and nurses.

The surroundings are beautiful. The climate is mild. There is central heating throughout. The annual rainfall is 30.5 inches, that is, less than the average for England.

The Fees are inclusive and vary according to the room occupied.

For particulars apply to THE SECRETARY, Ruthin Castle, North Wales.

Telegrams: Castle, Ruthin.

Telephone: Ruthin 66

Continued from page 622-G. C. Lloyd-Roberts, M.B., F.R.C.S.

\section{Acknowledgments}

It gives me pleasure to acknowledge the help given to me by members of the staffs of the Royal National Orthopaedic Hospital and St. George's Hospital whilst I was carrying out an investigation into osteoarthritis.

\section{REFERENCES}

BENNETT, G. A., WAINE, H., and BAUER, W. (1942), ' Changes in the Knee Joint at Various Ages,' New York: Commonwealth Fund.
COLLINS, D. H. (1949), 'The Pathology of Articular and Spipal Diseases,' London, Edward Arnold \& Co.

HARRISON, M. H. M., SCHAJOWICZ, F., and TRUETANJ. (1953), $\mathscr{f}$. Bone $\mathcal{F}$. Surg., 35-B, 598.

INGELMARK, B. E., and EKHOLM, R. (1948), 'A Study on Variations in the Thickness of Articular Cartilage in Association with Rest and Periodical Load: and Experimental Investigation on Rabbits,' Upsala Lakareforenings Fordhandlinger, $53,6 \mathrm{r}$.

KELLGREN, J. H., and MOORE, R. (1952), Brit. med. f., i, KEY, J. A. (1929), F. Bone F. Surg., II, 705 .

LINDELLS, J. W. (I953), Ibid, 35-B, 643 .

LLOYD-ROBERTS, G. C. (1953), Ibid, 35-B, 627

LLOYD-ROBERTS, G. C. (1955). Ibid, 37-B, 8.

MATTHEWS, B. F. (1953), Brit. med. F., ii, 660 